\title{
The role of chitin and chitosan in peripheral nerve reconstruction
}

\author{
Michał Bąk ${ }^{A-D}$, Olga N. Gutkowska ${ }^{A, B, D}$, Ewa Wagner ${ }^{B, C}$, Jerzy Gosk ${ }^{A-C, E, F}$ \\ Department of Traumatology, Clinical Department of Traumatology and Hand Surgery, Wroclaw Medical University, Wrocław, Poland \\ A - research concept and design; $B$ - collection and/or assembly of data; $C$ - data analysis and interpretation; \\ $D$ - writing the article; $E$ - critical revision of the article; $F$ - final approval of article
}

\section{Address for correspondence \\ Jerzy Gosk}

E-mail: jerzy.gosk@umed.wroc.pl

\section{Funding sources}

none declared

\section{Conflict of interest}

none declared

Received on June 08,2017

Revised on June 18, 2017

Accepted on July 03, 2017

\begin{abstract}
Chitin is a natural polysaccharide commonly found in nature and chitosan is its partially deacetylated derivative. The properties of both biopolymers allow their wide use in medicine and various industries. This paper presents the possibilities offered by chitin and chitosan for the creation of neurotubes utilized in peripheral nerve repair procedures. In the initial part of this manuscript, experimental studies on both polysaccharides carried out by numerous authors have been presented and their results have been discussed. Further, basic information on Reaxon ${ }^{\circledR}$ Nerve Guide, being the first chitosan tube approved for clinical use, is provided. Finally, existing limitations in the optimal use of chitosan tubes in peripheral nerve reconstruction have been pointed out. It is expected that modification of the properties of chitosan itself as well as enriching neurotubes with components of extracellular matrix, cells, growth factors and filaments will further improve the results of nerve regeneration obtained with chitosan-based nerve conduits.
\end{abstract}

Key words: artificial nerve conduit, chitosan nerve guide, nerve regeneration, nerve reconstruction
DOI

10.17219/pim/75653

\section{Copyright}

๑) 2017 by Wroclaw Medical University

This is an article distributed under the terms of the Creative Commons Attribution Non-Commercial License (http://creativecommons.org/licenses/by-nc-nd/4.0/) 
Chitin is a biopolymer commonly found in the exoskeletons of arthropods, the shells of crustaceans and insect cuticles. ${ }^{1-3}$ It is a linear homopolymer composed of $\mathrm{N}$-acetyl-D-glucosamine units that form $\beta$ - $(1 \rightarrow 4)$-linkages. ${ }^{2,3}$ Chitin is, after cellulose, the second most abundant polysaccharide in nature. ${ }^{4}$

Chitosan is obtained by the partial deacetylation of chitin. It is a polysaccharide composed of D-glucosamine and $\mathrm{N}$-acetyl-D-glucosamine units linked through 1-4 glycosidic bonds. ${ }^{5}$ In nature, chitosan is found in some fungi. ${ }^{2}$ It is commercially obtained by alkaline hydrolysis of chitin. ${ }^{3}$ The degree of acetylation of chitosan can range from 0 to $60 \% .^{3}$ Thanks to their advantageous properties, both chitin and chitosan are widely used in medicine and industry. ${ }^{1,6-8}$ These characteristics include: a "non-toxic character, biocompatibility, biodegradability, ease of creating various forms (films, sponges, fibres, hydrogels, porous scaffolds), chemical and enzymatic modifiability, antimicrobial properties, the capacity for controlled release of cytokines, extracellular matrix components and antibiotics, the ability to cause cell adherence, as well as to induce and maintain viability of tissue cells". ${ }^{1,4-7}$ The above-listed features prompted research on the possible uses of chitin and chitosan in peripheral nerve reconstruction.

\section{Experimental studies}

Itoh et al. examined in experimental conditions the properties of chitosan tubes prepared from crab Macrocheira kaempferi tendons. The tubes had circular and triangular cross-sections. Some of the tubes having a triangular cross-section had also laminin and laminin peptides (CDPGYIGSR or CSRARKQAASIKVAVSAD) adsorbed, which enhanced migration and attachment of Schwann cells as well as neurite outgrowth. ${ }^{9}$ Rat sciatic nerves, in which $10 \mathrm{~mm}$ defects had been created, were used in the experiment. The defects were bridged with the above-described tubes, measuring $15 \mathrm{~mm}$ in length. Isografts were used in the control group. The investigation of the tubes 2-4 weeks after the implantation revealed tube infiltration with inflammatory cells and macrophages, which was associated with the initial period of the tube wall fragmentation process. ${ }^{9}$ After 6 weeks, the authors found evidence of nerve regeneration in both tubes made of unblended chitosan (circular and triangular) but it took place mainly in the center of the tube, whereas in the tubes enriched with laminin or laminin peptides, regeneration proceeded along the inner wall of the tube. However, in neither group was the degree of regeneration comparable to that obtained with the use of isografts. ${ }^{9}$ Another interesting conclusion drawn by the authors of the discussed study was that triangular tubes had higher mechanical strength than circular tubes. The latter had a higher tendency to collapse. ${ }^{9}$
The results obtained encouraged the Japanese researchers to continue their studies. Wang created a chitosan nonwoven nano/microfiber mesh tube with the use of an electro-spinning method. ${ }^{6}$ The bilayered tube contained an outer layer of chitosan film and an inner layer of chitosan nano/microfiber mesh. In this experiment on rat sciatic nerves with a $10 \mathrm{~mm}$ defect, the authors used:

1. Nano/microfiber mesh tubes with a deacetylation rate of 78 or $93 \%$,

2. Bilayered tubes with a nano/microfiber mesh inner structure with a deacetylation rate of 78 or $93 \%$ and a film outer layer with deacetylation rate of $93 \%$,

3. Film tubes with a deacetylation rate of $93 \%$.

Isografts were used in the control group. ${ }^{6}$ At 5 weeks after the implantation, fragmentation of the nano/microfiber mesh began. This process was accompanied by an inflammatory response manifested by gathering of macrophages around the tube wall. A faster biodegradation rate was observed for the chitosan nano/microfiber mesh with a deacetylation rate of $78 \%$. These tubes collapsed over time causing narrowing of the tube lumen. By contrast, chitosan nano/microfiber mesh tubes with a deacetylation rate of $93 \%$ kept their shape for as long as 15 weeks after the implantation. At the same time, the authors pointed out that the compressive strength of both the bilayered chitosan tube and the film tube was significantly greater than that of the chitosan nano/microfiber mesh. ${ }^{6}$ A conclusion can be drawn that the mechanical strength of the bilayered tube depended mainly on the film tube. On the other hand, when the functional results were analyzed, the highest number of myelinated axons and the greatest total axon area were found in the nano/microfiber mesh tubes with a deacetylation rate of $93 \%$. Thanks to the electro-spinning method used in their preparation process, the mechanical properties of these tubes were sufficient to support regenerating axons. A single-layered wall made the exchange of nutrients and the excretion of metabolic waste products easier. ${ }^{6}$

The influence of the degree of acetylation of chitosan on its properties was also noted by other authors. Freier et al. studied the compressive strength of chitin gel tubes with an acetylation rate of $94 \%$ and chitosan tubes with an acetylation rate of 18,3 and $1 \% .^{2}$ The chitin tubes initially had high compressive strength but they soon lost it as their degradation proceeded. The compressive strength of the chitosan tubes rose with the decrease of acetylation rate. ${ }^{2}$ According to the authors, a very low acetylation rate of chitosan is associated with high mechanical strength and a slower degradation process as well as increased viability and adhesion properties of lumbar dorsal root ganglion cells placed on the chitosan film., ${ }^{2,3}$ Freier et al. expressed the opinion that the main factor determining cell compatibility with chitosan is its charge, which depends on the amount and availability of amine groups., ${ }^{2,3}$ The charge density of chitosan increases with the decreasing degree of acetylation, leading to greater cell adhesion., ${ }^{2,3}$ 
In the study on rat sciatic nerves with a $10 \mathrm{~mm}$ defect conducted by Haastert-Talini et al., it was determined that a degree of acetylation around 5\% is optimal for nerve regeneration. ${ }^{10}$ Chitosan tubes with an acetylation rate of $2 \%$ were not able to sustain regenerating axons, whereas tubes with an acetylation rate of $20 \%$ succumbed to degradation too early and had low mechanical stability. ${ }^{10}$ Similarly, Gonzalez-Perez et al. in their study concluded that a degree of acetylation of chitosan of $5 \%$ favored nerve regeneration when compared to a lower degree of acetylation (2\%). ${ }^{11}$ The study was conducted on rat sciatic nerves with a $15 \mathrm{~mm}$ defect. ${ }^{11}$

The beneficial effect on nerve regeneration can be enhanced not only by a modification of chitosan properties but also by enriching the neurotubes with certain substances, e.g. laminin, growth factors (glial cell line-derived nerve growth factor - GDNF) or cells (bone marrow stem cells - BMSCs). ${ }^{7,12,13}$ Laminin-1 is a natural extracellular matrix glycoprotein (molecular weight, $800 \mathrm{kDa}$ ), that enhances neural cell attachment, differentiation and neurite outgrowth.7,12 Certain domains (YIGSR, IKVAV, RGD) are responsible for these properties of laminin. ${ }^{7,9}$ Both laminin and the above-mentioned peptides were used in many experimental studies to enhance the chitin/chitosan effect on nerve regeneration. ${ }^{9,12,14}$ Continuing their research, the Japanese scientists investigated the possibility to further modify the properties of the tubes. They suggested introducing glycine spacers into the YIGSR sequence. ${ }^{7}$ After creation of the amino acid sequences CGGYIGSR and CG6YIGSR, they were covalently joined with a nano/microfiber mesh fabricated with the electro-spinning method. This structure created the inner layer of the tube. The outer layer was made of chitosan film. The experiment was conducted on rat sciatic nerves with a $15 \mathrm{~mm}$ defect with the use of the following tubes: 1) bilayered chitosan tube, 2) bilayered chitosan tube with CYIGSR sequence, 3) bilayered chitosan tube with CG2YIGSR sequence, 4) bilayered chitosan tube with CG6YIGSR sequence. Isografts were used in the control group. The autopsies were carried out after 5 and 10 weeks. In the first group (non-treated tube), the number of axons was limited and they could be found in the center of the tube. In the laminin-peptide-treated groups, the number of regenerating axons was higher and many of them adhered to the inner wall of the tube. The best results were obtained by increasing the spacer group length (CG6YIGSR), but still they were inferior to those in the control group (isograft). ${ }^{7}$

Patel et al. in their experimental studies, used chitosan tubes enriched not only with laminin, but also with glial cell line-derived nerve growth factor (GDNF). ${ }^{12}$ GDNF provides trophic support to motor neurons, promotes axon regeneration and prevents the atrophy of motor neurons. ${ }^{15,16}$ Similarly to laminin, GDNF has the capacity to relieve neuropathic pain. ${ }^{17,18}$
Three types of chitosan tubes were used in this study: 1) C nerve guide (unblended chitosan guide); 2) LC nerve guide (laminin-chitosan guide); 3) GLC nerve guide (GDNF-laminin-chitosan guide). Autografts were used in the control group. The experiment was carried out on rat sciatic nerves with a $10 \mathrm{~mm}$ defect. After 12 weeks of observation, it was determined that functional recovery results were comparable in the $\mathrm{LC}$ and GLC groups and much better than in the C group, in which unblended chitosan nerve guide was used. These findings confirmed previous conclusions made by the same authors regarding the limited potential for nerve regeneration with the use of chitosan tubes alone. ${ }^{19}$

A different modification of chitosan-based tube was proposed by $\mathrm{Hsu}$ et al., who created a laminin-coated chitosan multi-walled nerve conduit combined with bone marrow stem cells (BMSCs). ${ }^{13}$ In this experiment, $10 \mathrm{~mm}$ defects in rat sciatic nerves were bridged with: 1) empty silicone conduit, 2) laminin (LN)-modified chitosan scaffold in silicone conduit, 3) laminin (LN)-modified chitosan scaffold with BMSCs in silicone conduit. The LN-modified chitosan film $(10 \times 10 \mathrm{~mm})$ was rolled up and put into the silicone conduit measuring 1.57 (inner diameter) $\times 2.41$ (outer diameter $) \times 14 \mathrm{~mm}$. Sciatic nerve stumps were inserted into the conduit to a depth of $2 \mathrm{~mm}$. Autopsies were carried out after 16 weeks. In group 2, the tube was surrounded by granulation hyperplasia tissue, which was mainly composed of eosinophils and macrophages. ${ }^{13}$ No such phenomenon was observed in group 3, in which the tubes were enriched with BMSCs. The authors concluded: "BMSCs suppressed neuronal cell death and promoted regeneration by suppressing the inflammatory and fibrotic response induced by chitosan after long-term implantation". ${ }^{13}$

Lauto et al. suggested another use of chitosan in peripheral nerve repair. ${ }^{20}$ The authors developed a novel adhesive composed of chitosan, indocyanine green, acetic acid and water. This chitosan adhesive was then used in an experimental study on rats to repair tibial nerve defects with the use of a laser. The laser fluence applied to the operated nerves did not exceed $46 \mathrm{~J} / \mathrm{cm}^{2}$. In the course of the experiment, good quality nerve repair was achieved, with tensile strength of $12.5 \pm 2.6 \mathrm{kPa}$. Thus, the connection between the nerve stumps was stronger than provided by fibrin glue, the adhesive strength of which is estimated at $\sim 8 \mathrm{kPa} .{ }^{20}$

The authors highlighted a number of advantages of chitosan that make it especially effective in this type of nerve repair procedures, including its insolubility in physiological fluids as opposed to fibrin glue, its adhesiveness prior to laser activation and its hydrophilic properties. ${ }^{20}$ The chitosan adhesive is based on polysaccharide, which eliminates the risk of viral infection, unlike in the case of hemo-derived proteins. ${ }^{20}$ 


\section{Clinical uses of chitosan}

A chitosan-based nerve conduit under the name Reaxon ${ }^{\circledR}$ Nerve Guide manufactured by Medovent $\mathrm{GmbH}$ (Mainz, Germany), in accordance with the international standard DIN EN ISO 13485, was launched onto the market in June, 2014. The length of the tube is $30 \mathrm{~mm}$, with a range of inner diameter sizes available: 2.1, 3.0, 4.0, 5.0 and $6.0 \mathrm{~mm}$. These diameters are observed in the dry state of the tube and increase by 0.1 to $0.4 \mathrm{~mm}$ after hydration. Flexibility and resistance to collapse are amongst the advantages of the tube, as declared by the manufacturer. A transparent tube wall makes insertion of nerve stumps easier and its hydrogel character facilitates suturing nerve stumps to the tube. Electrostatic interaction between the positively-charged surface of Reaxon ${ }^{\circledR}$ Nerve Guide and negatively-charged biomolecules and cell components favors nerve regeneration. Reaxon ${ }^{\circledR}$ Nerve Guide is designed to aid in the repair of nerve defects not exceeding $26 \mathrm{~mm}$ in clinical settings. Intraoperatively, after having chosen an adequate inner tube diameter, the tube is placed in sterile saline solution for at least $10 \mathrm{~min}$. The nerve stumps are connected to the tube with the use of monofilament non-absorbable size $8-0$ sutures. The tube is filled with saline solution. ${ }^{21}$

Medovent $\mathrm{GmbH}$ has run 2 clinical investigation programs dedicated to the clinical uses of Reaxon ${ }^{\circledR}$ Nerve Guide since 2015. The first program, entitled "A controlled, randomized, comparison, blind evaluation of repair of digital nerve lesions in men using an implanted Reaxon ${ }^{\circledR}$ Nerve Guide", will comprise 76 patients with traumatic digital nerve defects, not exceeding $26 \mathrm{~mm}$ in length. The estimated study completion date is May 2018.

The other study, designed as a randomized, double-blind, controlled, multicenter trial, was originated in February, 2015. The study is being conducted concurrently at 3 trauma centers in Ludwigshafen, Frankfurt am Main and Bochum and comprises cases of acute digital nerve injuries (up to $72 \mathrm{~h}$ from the injury). One hundred patients are planned to be included in the study. In a half of them, a simple "end-to-end" repair will be conducted, while in the other half a $1 \mathrm{~cm}$-long chitosan tube with a diameter of $2.1 \mathrm{~mm}$ will additionally be used. Sutures 9-0 will be used in both groups. The outcomes will be evaluated after 3, 6, 12 and 24 months. The duration of the project is estimated at 36 months, until the completion of all follow-up examinations. ${ }^{22}$

Reaxon ${ }^{\circledR}$ Nerve Guide was also used by Fornasari et al. in experimental studies on rats. The authors examined the influence of the presence of skeletal muscle fibers on nerve regeneration. ${ }^{23}$ The rats were divided into 2 groups. In one group, an $8 \mathrm{~mm}$ median nerve defect was repaired with a $10 \mathrm{~mm}$-long chitosan tube. In the other group, a longitudinal piece of the pectoralis major muscle was inserted in each tube. Autografts were used in the control group. Both early $\left(7^{\text {th }}, 14^{\text {th }}\right.$ and $28^{\text {th }}$ day after the op- eration) and late ( $3^{\text {rd }}$ month after the operation) control examinations were performed. The authors presumed that the presence of muscle tissue inside the tube, being a source of neuregulin 1 (a factor enhancing Schwann cell livability and activity) would have a pronounced positive effect on the regeneration process. It turned out that with short defects, both a chitosan tube alone and the tube enriched with skeletal muscle tissue were effective in promoting the return of nerve function. ${ }^{23}$

\section{Summary}

It is beyond doubt that chitin, and even more so chitosan, constitute an excellent basis for creation of an optimal neurotube. The possibility to change the degree of acetylation of chitosan makes possible the modification of its mechanical properties and the degradation rate of the tube. ${ }^{6}$ Modern technological capabilities enable the creation of a tube made of chitosan fibers measured on the nanometric scale. ${ }^{6}$ As a result, a 3-dimensional porous microstructure can be obtained that imitates extracellular matrix (ECM). The porosity of the tube wall makes the exchange of nutrients and the excretion of metabolic waste products easier. ${ }^{6,7}$ Moreover, such a nano/microfibrous structure has a high surface area-to-volume ratio. Such a large surface area allows effective binding with other substances, e.g. laminin - a protein that is a natural constituent of extracellular matrix, cells (BMSCs) and growth factors (GDNF). 7,12,13

There are several reasons for enriching chitosan tubes with other substances. Firstly, the properties of the added substances accelerate the regeneration processes. Secondly, they minimize the side effects of chitosan degradation. Chitosan as a polymer and its short chains, unlike its degradation fragments, do not cause an inflammatory response. ${ }^{24,25} \mathrm{Hsu}$ et al. demonstrated that the chitosan fragments produced by degradation were able to induce inflammation, which caused apoptosis of newly generated cells, and proliferation of fibrous tissue around the conduit. ${ }^{13}$ Experimental studies have resulted in launching a chitosan tube onto the market for clinical use: Reaxon ${ }^{\circledR}$ Nerve Guide. ${ }^{21,26}$ It allows the repair of short nerve defects, when the nerve diameter does not exceed $6.0 \mathrm{~mm}$. The repair of nerve defects in nerves with a larger diameter still constitutes a challenge. ${ }^{27,28}$ Obtaining satisfactory regeneration is such cases will only be made possible with the use of a technologically advanced neurotube. An "ideal nerve conduit" is expected to have the following characteristics: biodegradability, porosity and permeability of the tube wall, presence of an inner scaffold made of fibers or filaments, the capacity to sustain cell livability and promote cell migration, the ability to secrete growth factors and electrical conductivity. ${ }^{29-32}$ As the analysis of the presented studies indicates, chitosan, thanks to its versatile properties, could be a component of such an ideal neurotube. 


\section{References}

1. Muzzarelli RAA. Chitins and chitosans for the repair of wounded skin, nerve, cartilage and bone. Carbohydr Polym. 2009;76:167-182.

2. Freier T, Montenegro R, Shan Koh H, Shoichet MS. Chitin-based tubes for tissue engineering in the nervous system. Biomaterials. 2005;26:4624-4632

3. Freier T, Koh HS, Kazazian K, Shoichet MS. Controlling cell adhesion and degradation of chitosan films by $\mathrm{N}$-acetylation. Biomaterials. 2005;26:5872-5878.

4. Crompton KE, Goud JD, Bellamkonda RV, et al. Polylysine-functionalised thermoresponsive chitosan hydrogel for neural tissue engineering. Biomaterials. 2007; 28:441-449.

5. Lu G, Kong L, Sheng B, Wang G, Gong Y, Zhang X. Degradation of covalently cross-linked carboxymethyl chitosan and its potential application for peripheral nerve regeneration. Eur Polym J. 2007;43:3807-3818.

6. Wang W, Itoh S, Matsuda A, et al. Influences of mechanical properties and permeability on chitosan nano/microfiber mesh tubes as a scaffold for nerve regeneration. J Biomed Mater Res A. 2008, 84, 557-566.

7. Wang W, Itoh S, Matsuda A, et al. Enhanced nerve regeneration through a bilayered chitosan tube: the effect of introduction of glycine spacer into the CYIGSR sequence. J Biomed Mater Res A. 2008;85:919-928.

8. Mazurek P, Kuliński S, Gosk J. Możliwości wykorzystania chityny i chitozanu w leczeniu ran. Polim Med. 2013;43:297-302.

9. Itoh S, Suzuki M, Yamaguchi I, et al. Development of a nerve scaffold using a tendon chitosan tube. ArtifOrgans. 2003;27:1079-1088.

10. Haastert-Talini K, Geuna S, Dahlin LB, et al. Chitosan tubes of varying degrees of acetylation for bridging peripheral nerve defects. Biomaterials. 2013;34:9886-9904. doi: 10.1016/j.biomaterials.2013.08.074.

11. Gonzalez-Perez F, Cobianchi S, Geuna S, et al. Tubulization with chitosan guides for the repair of long gap peripheral nerve injury in the rat. Microsurgery. 2015;35:300-308. doi: 10.1002/micr.22362.

12. Patel M, Mao L, Wu B, Vandevord PJ. GDNF-chitosan blended nerve guides: a functional study. J Tissue Eng Regen Med. 2007;1:360-367.

13. Hsu SH, Kuo WC, Chen YT, et al. New nerve regeneration strategy combining laminin-coated chitosan conduits and stem cell therapy. Acta Biomater. 2013;9:6606-6615. doi: 10.1016/j.actbio.2013.01.025.

14. Suzuki M, Itoh S, Yamaguchi I, et al. Tendon chitosan tubes covalently coupled with synthesized laminin peptides facilitate nerve regeneration in vivo. J Neurosci Res. 2003;72:646-659.

15. Jubran $M$, Widenfalk J. Repair of peripheral nerve transections with fibrin sealant containing neurotrophic factors. Exp Neurol. 2003;181:204-212.

16. Chen ZY, Chai YF, Cao L, Lu CL, He C. Glial cell line-derived neurotrophic factor enhances axonal regeneration following sciatic nerve transection in adult rats. Brain Res. 2001;902:272-276.

17. Grimpe B, Silver J. The extracellular matrix in axon regeneration. Prog Brain Res. 2002;137:333-349.

18. Wang R, Guo W, Ossipov MH, Vanderah TW, Porreca F, Lai J. Glial cell line-derived neurotrophic factor normalizes neurochemical changes in injured dorsal root ganglion neurons and prevents the expression of experimental neuropathic pain. Neuroscience. 2003;121:815-824.

19. Patel M, Vandevord PJ, Matthew H, Wu B, DeSilva S, Wooley PH. Video-gait analysis of functional recovery of nerve repaired with chitosan nerve guides. Tissue Eng. 2006;12:3189-3199.

20. Lauto A, Foster LJ, Avolio A, et al. Sutureless nerve repair with laser-activated chitosan adhesive: A pilot in vivo study. Photomed Laser Surg. 2008;26:227-234. doi: 10.1089/pho.2007.2131.

21. Medovent. Reaxon ${ }^{\circledR}$ Nerve Guide-Medovent. http://medovent.de/ wp-content/uploads/2015/12/REAXON_GB_mail.pdf. Accessed August 28, 2017.

22. Neubrech F, Heider S, Harhaus L, Bickert B, Kneser U, Kremer T. Chitosan nerve tube for primary repair of traumatic sensory nerve lesions of the hand without a gap: study protocol for a randomized controlled trial. Trials. 2016;17:48. doi: 10.1186/s13063-015-1148-5.

23. Fornasari BE, Gambarotta G, Ronchi G, et al. Chitosan tubes enriched by skeletal muscle for peripheral nerve regeneration. $6^{\text {th }}$ Vienna Symposium on Surgery of Peripheral Nerves. 17-19.03.2017. Poster; 16.
24. Reese TA, Liang HE, Tager AM, et al. Chitin induces accumulation in tissue of innate immune cells associated with allergy. Nature. 2007;447:92-96.

25. Baldrick P. The safety of chitosan as a pharmaceutical excipient. Regul Toxicol Pharmacol. 2010;56:290-299. doi: 10.1016/j.yrtph.2009.09.015.

26. Shapira $Y$, Tolmasov $M$, Nissan $M$, et al. Comparison of results between chitosan hollow tube and autologous nerve graft in reconstruction of peripheral nerve defect: An experimental study. Microsurgery. 2016;36:664-671. doi: 10.1002/micr.22418.

27. Gosk J, MazurekP, Reichert P, Wnukiewicz W, Rutowski R. Możliwości wykorzystania materiałów nie ulegających degradacji jako tub w rekonstrukcjach nerwów obwodowych. Polim Med. 2010;40:3-8.

28. Gosk J, Urban M, Ratajczak K, Wiacek R, Rutowski R. Zastosowanie syntetycznych polimerów ulegających biodegradacji w rekonstrukcjach nerwów obwodowych. Polim Med. 2010;40:3-9.

29. Jiang X, Lim SH, Mao HQ, Chew SY. Current applications and future perspectives of artificial nerve conduits. Exp Neurol. 2010;223:86-101. doi: 10.1016/j.expneurol.2009.09.009.

30. de Ruiter GC, Malessy MJ, Yaszemski MJ, Windebank AJ, Spinner RJ. Designing ideal conduits for peripheral nerve repair. Neurosurg Focus. 2009;26:E5. doi: 10.3171/FOC.2009.26.2.E5.

31. Ichihara S, Inada Y, Nakamura T. Artificial nerve tubes and their application for repair of peripheral nerve injury: An update of current concepts. Injury. 2008;39 Suppl:S29-S39. doi: 10.1016/j.injury.2008.08.029.

32. Johnson EO, Soucacos PN. Nerve repair: Experimental and clinical evaluation of biodegradable artificial nerve guides. Injury. 2008;39 Suppl:S30-S36. doi: 10.1016/j.injury.2008.05.018. 